\title{
Implementation of Problem-Based Learning in Basic Statistical Concepts using Web-Based Apps
}

\author{
Ahmad, Zulkifley Mohamed, F. E. Subekti
}

\begin{abstract}
The aim of this article is to describe students' cognitive abilities and responses to problem-based learning in the basic statistical concepts when web-based apps is used. Web-based apps were utilized via the Mentimeter application and Google Forms. The application is intended to familiarize students' with the process of data collection, data presentation, and problems solving. The students' worksheet and learning response questionnaires were used in data colllection. The data were then described quantitatively. The results revealed that by ultilizing Mentimeter and Google Forms in problem-based learning will enhance students' understanding and skills in the basic statistical concepts. Additionally, students had a positive attitude toward learning statistics. Student' tend to be more enthusiastic about their studies.
\end{abstract}

Keywords: Google Forms, Mentimeter, and Problem- Based Learning

\section{INTRODUCTION}

$\mathrm{T}$ echnology is an indispensible component of 21st-century education. Due to students' ability to actively search, evaluate, and filter information, technology allows them to study independently on a global scale [1]. The use of technology in education will have an impact, whether positive or negative. Several advantages of integrating technology in teaching and learning (T\&L) include greater student engagement, more efficient learning, and increased student satisfaction and interest in learning [2]. Additionally, for technology-assisted learning to be effective, the technology must be focused on the desired learning objectives, and the emphasis on using technology should not be too wide [3]. Meanwhile, the negative consequence is that students spend more time on social media platforms (such as Facebook, Twitter, and YouTube) than on academic work [4]. Additionally, students are often more concerned with the technical aspect than with the actual content [5].

Students enrolling in the mathematics education program at Universitas Muhammadiyah Purwokerto, Indonesia

Manuscript received on August 04, 2021.

Revised Manuscript received on August 11, 2021.

Manuscript published on August 30, 2021.

* Correspondence Author

Ahmad*, Universitas Muhammadiyah Purwokerto, Kembaran Banyumas, Indonesia. Email: ahmad@ump.ac.id

Zulkifley Mohamed, Universiti Pendidikan Sultan Idris, 35900 Tanjong Malim Perak, Malaysia. Email: zulkifley@fsmt.upsi.edu.my

F.E. Subekti, Universitas Muhammadiyah Purwokerto, Kembaran Banyumas, Indonesia. Email: efitrians@gmail.com

(c) The Authors. Published by Blue Eyes Intelligence Engineering and Sciences Publication (BEIESP). This is an open access article under the CC BY-NC-ND license (http://creativecommons.org/licenses/by-nc-nd/4.0/)
(UM.P) are required to take a basic statistics course. This course

intends to: (i) prepare students to teach statistics in secondary schools; and (ii) resolve problems associated with data collection and presentation, either manually or using specialized software. Among the topics taught in basic statistics course are fundamental statistics principles, data presentation, frequency distribution tables, measures of location, dispersion and distribution, correlation analysis and inferential data analysis. The basic statistics course also focuses on data collecting, the differences between descriptive and inferential statistics, sampling techniques, data visualization, and the application of statistics in daily life,

Through the pilot study conducted among students in five classses at Indonesia secondary schools, it was found that (i) students understand data collection and statistical analysis only on a theoretical level; (ii) students' grasp the concepts of the material being taught, but were struggling with the calculation; (iii) students' were struggling with questions that differ from the examples; and (iv) students' used the hand phone exclusively for communication and social media.

Meanwhile, when the basic statistics course was taught at UM.P during the pilot study, the following issues were discovered: (i) students' were capable to present data in the form of diagrams. However, it was difficult for them to justify the used of specific diagrams; (ii) students' experienced with data collection and presentation was still lacking; and (iii) an explanation of the basic statistical concepts at the theoretical level causes students' difficulty when asked to analyze and solve real life problems.

Based on these considerations, the use of appropriate T\&L method that teaches students how to deal with a variety of problems in statistics is crucial. One of the T\&L method that may be used is Problem-Based Learning (PBL) with web-based apps. PBL is a method of instruction that focuses on problems given by educators and in which students will work together to select and decide on the most effective way to solve the problems [6]. The emphasis on autonomous learning and students' active participation in problem solving, it is the necessitates at the certain time to utilize a scaffolding [7].

Rather than resolving problems, PBL emphasizes the development of knowledge and understanding through suitable challenges [8]. PBL enables students to collaborate on real-world problems [9].

Published By:

Blue Eyes Intelligence Engineering

\& Sciences Publication

(C) Copyright: All rights reserved. 
According to [10], PBL consisted of five stages: (i) to establish a one-of-a-kind problem or challenge; (ii) investigate the problem by using inquiry approach and place the findings into practise; (iii) through collaborative activities, students will investigate and assess the ideas.; (iv) apply the inquiry process to fine-tune findings; and (v) evaluate the findings. Its application is centered on five main themes, namely: (i) a focus on the issues; (ii) a student-centered approach; (iii) self-initiated activities; (iv) self-reflection; and (v) lecturers as facilitators [11]. With these five essential characteristics, it is hoped that students would develop an aptitude for problems solving, take the initiative to resolve problems on their own, and be able to reflect on their own answers.

\section{OBJECTIVE}

This article explores students' understanding abilities and responses to PBL on basic statistics course by utilizing web-based apps. The web-based apps are comprised of the Mentimeter application and Google Forms.

\section{METHOD}

This is a quantitative descriptive research. The ability of students to understand and respond to the used of web-based apps in PBL was investigated. The survey data were presented in the form of tables, graphs and descriptively. The information provided was derived from students' worksheets and the results of a learning response questionnaire. Google forms were used to construct the questionnaire and data collections. Twenty-two undergraduate students of Universitas Muhammadiyah Purwokerto, Indonesia who have completed basic statistics course were participating in the research.

\section{FINDING AND DISCUSSION}

In this research, the initial step of conducting PBL using web-based apps were engaging the students to use Mentimeter and Google forms. The process of learning begins with students' participation in the data collection process. The first stage of data collection was made through mentimeter platform. Students were asked two simple questions, namely: (i) three things they notice about mathematics; and (ii) why they continue their studies at the University of Muhammadiyah, Purwokerto. The respond to this two questions in the survey were available at www.mentimeter.com with the number 7738 4. The survey's findings are as follows:

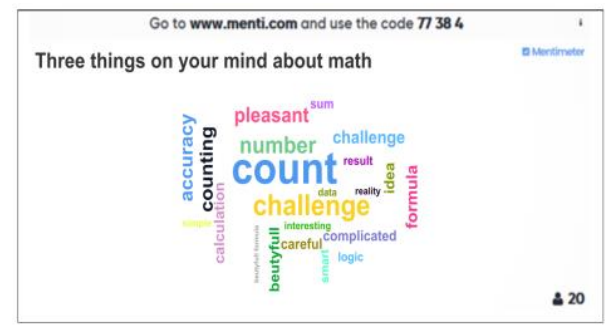

Fig. 1. Results of the survey using the first question in Mentimeter.

Only twenty students responded to the question "three things they notice about mathematics" in the initial survey, as illustrated in Fig. 1. Numerous answers were conceivable, among them were: mathematics is involved with numbers, formulas, and calculations; it was also appealing, cool, and pleasant; yet it requires precision, logic, and was difficult. The survey results were used to demonstrate to the students that mathematics can be viewed from a variety of perspectives. This is a challenge for future teachers to find out how to make mathematics engaging, problem-based, and not just about formulae.

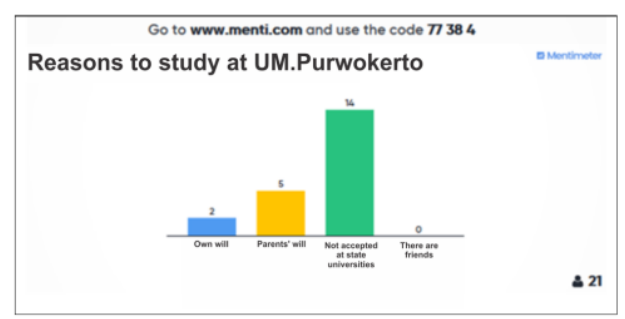

Fig. 2. Survey results for the second question using mentimeter

The second question was addressed to twenty-one of the twenty-two students through the mentimeter platform. According to the survey results in Fig. 2, the majority of students enrolled in the mathematics education program at Universitas Muhammadiyah, Purwokerto after being rejected by a state university; five students enrolled in the program at the request of their parents, and two students did so on their own. The difference in the number of students who completed the survey was caused by the fact that their cellphones were disconnected from the internet during the survey. In addition, by using a mentimeter allowed students to actively participate in data collection process as it introduce them to a method of applying statistics in real life. It also teaches students that data must be provided in order to gain knowledge, as illustrated in Fig. 1 and 2 above.

In additament, students were introduced to the data collection process, which includes supplying biographical information through the used of Google Forms. The following fields in the biographical information section were completed by the students: (i) name; (ii) identification number; (iii) gender; (iv) blood group; (v) parental education; (vi) parental income; (vii) height; (viii) wake-up time; and (xi) number of siblings. Students submitted their biographical information online at http://gg.gg/OrientasiB. Fig. 3 shows the student activities using the biographical information input process.

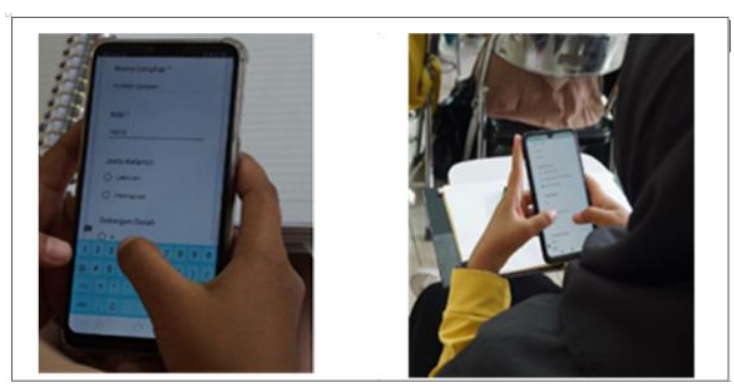

Fig. 3. The procedure of entering biographical information through the URL http://gg.gg/OrientasiB.

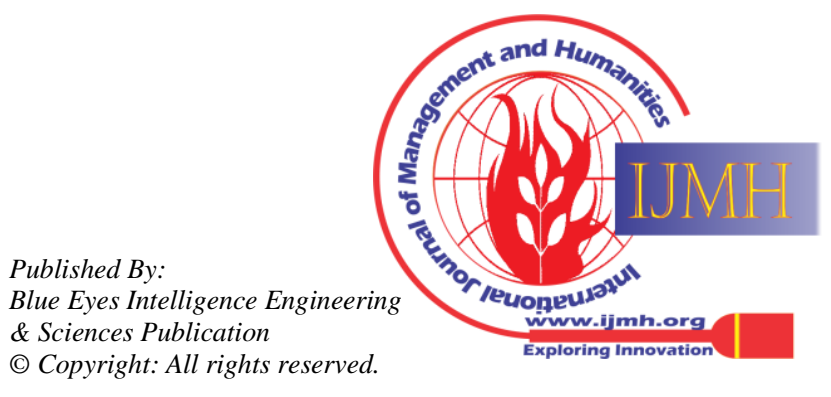


Students completed biographical information on an iPhone or an Android smartphone, as was the case with previous data collection. Students had no difficulty in filling out their biographical information. The following were some of the reasons why biographical information should be entered through Google forms: (i) to gather data using web-based apps; (ii) to introduce pie chart to present data; and (iii) as a problem-solving tool for different types of data depicted on the scale and how to acquire them.

The LCD screen shows the data collecting and presentation results after the data collection process. Fig. 4 depicts the data collection results in a pie chart.

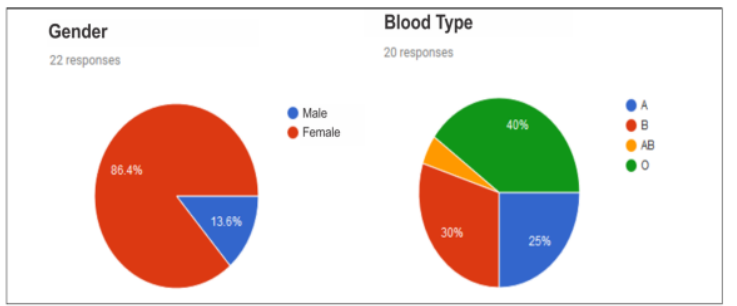

Fig. 4. The presentation of gender and blood group type.

Fig. 4 illustrates students' gender and blood type. 86.4\% of the students were female, whereas $13.6 \%$ were male. Two students did not provide their blood group information, most likely because they were ignorant of their blood type. According to the findings, the majority of students with blood type $\mathrm{O}$. In this research, gender and blood type data were used to demonstrate to the students that there was a different type of scale in measuring data. Hints were given to the students in the form of enticing questions, such as following: (i) is there a distinction between gender? (ii) Is there a distinction between blood types $\mathrm{A}, \mathrm{B}, \mathrm{AB}$, and $\mathrm{O}$ ? (iii) Are men superior to women? (iv) Is blood type $O$ superior to blood types A, B, or AB?

Additionally, Fig. 5 shows the data on family level of education and incomes. Students were given the same questions as in the previous activitiy. The questions posted to the students were: (i) what is the highest level of education of your parents; and (ii) how much your parents earn a month, more than Rp. 5,000,000, between Rp. 2,500,000 and Rp. $5,000,000$, or earning less than Rp. 2,500,000? The purpose of these questions enables the students to understand and differentiate between nominal and ordinal data. In this research, students were also requested to present the data graphically using Google Forms as shown in Fig. 5.

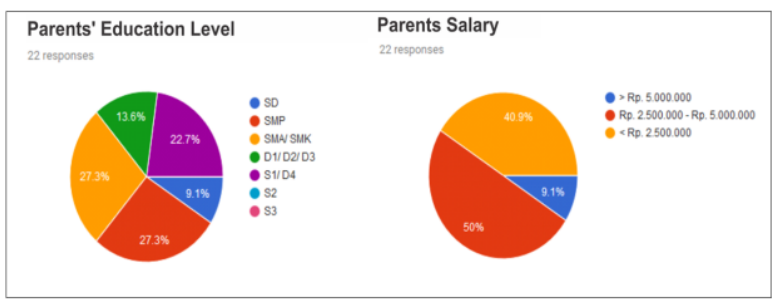

Fig. 5. Parents education and income.

The presented data done by students shows that $27.3 \%$ of their parents attended a junior high school/ high school/ vocational school, 22.7\% hold a bachelor's degree / D4, and the remaining hold an elementary school certificate or diploma (D1 /D2 /D3). Majority of parents earned between Rp. 2,500,000 and Rp. 5,000,000. 50\% earn less than Rp.
2,500,000, while 9.1\% earn more than Rp. 5,000,000 in terms of wages.

Meanwhile, to demonstrate the various types of data that was used as interval and ratio scales, data on wake up time and number of siblings were utilized as shown in Fig. 6 and 7.

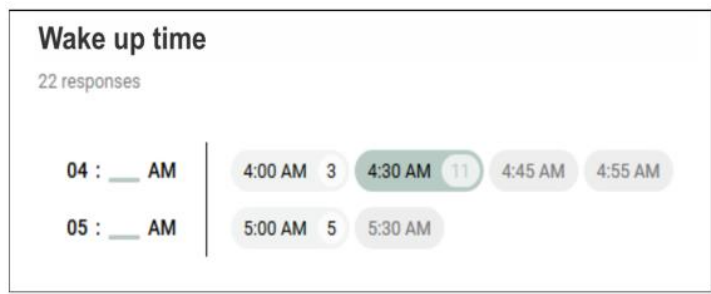

Fig. 6. Data visualization of wake up time.

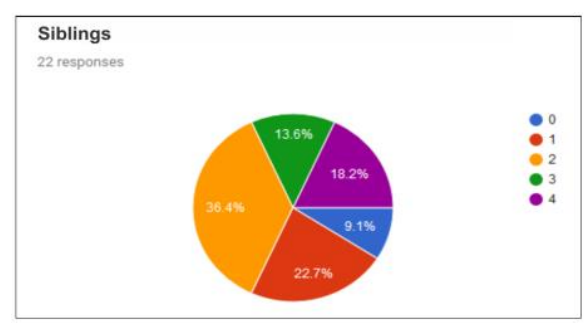

Fig. 7. Data visualization of the number of siblings.

Some of the prompt questions relating to data presentation were as follows: (i) is there any difference between those who wake up at 4:00 AM and 5:00 AM?; (ii) is there any difference between wake up time for those with different number of siblings?; and (iii) do your wake up time associate with the number of siblings?

Apart from serving as crucial information, this section discusses the different types of interval and ratio data. Fig. 6 and 7 above are used to teach students about the types of data available, the purpose of displaying data, and how to extract information using pie charts.

Following that, during the phase of problem solving activities, students were splitted into six groups consisted of of three to four students in each group. Each group was provided with a student worksheet comprised of four problems. Students are expected to be able to distinguish between descriptive and inferential statistics in Problem 1, describe the different types of data and their rationales in Problem 2, solve problems involving the application of statistics in everyday life in Problem 3, and provide the examples of data usage as a basis for planning in Problem 4.

The next phase was a self-contained inquiry (individual or group). Fig. 8 illustrates activities pertaining to the problems solving conversation procedure.
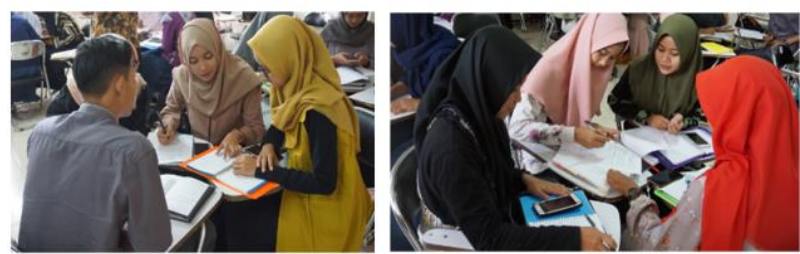

Fig. 8. Problems solving activities. 
As shown in Fig. 8, students were passionate, proactive, and cooperative while addressing a given problems. Along with enriching educational materials, students may apply their digital literacy skills to search out other information that will assist them to solve the pertaining problems. Following that, the lecturer who monitors the discussion activities will assist the groups that require assistance during the group discussion.

The next step was the group presentation of the discussion outcomes. Fig. 9 illustrate some images from the process of the group presentation.
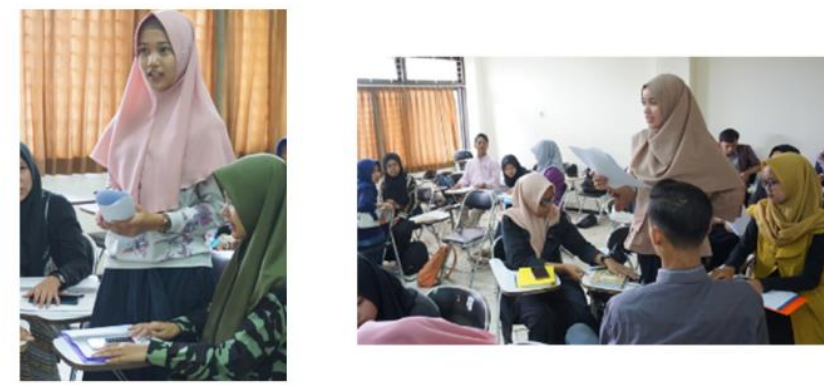

Fig. 9. The procedure for providing problem-solving outcomes.

During the presentation, the students expressed their thoughts with confidence about the outcome of their activities, despite the fact that they were in their first and cooperation skills than those in the control group.

Additionally, the students were given a test to assess their four problems scenario (Problem 1, 2, 3 and 4) as described earlier. The outcome of the assessment is displayed in Table-1.

Table- I: Assessment of students' content knowledge of basic statistical concepts.

\begin{tabular}{|c|l|c|c|c|c|c|c|c|}
\hline \multirow{2}{*}{$\begin{array}{l}\text { Item } \\
\text { Number }\end{array}$} & Indicator & $\mathbf{1}$ & $\mathbf{2}$ & $\mathbf{3}$ & $\mathbf{4}$ & $\mathbf{5}$ & $\mathbf{6}$ & Percentage \\
\hline 1 & $\begin{array}{l}\text { Differences between } \\
\text { descriptive and inferential } \\
\text { statistics. }\end{array}$ & 10 & 10 & 10 & 10 & 10 & 10 & 100 \\
\hline 2 & $\begin{array}{l}\text { Indicate different types of } \\
\text { data and the purpose for its } \\
\text { collection. }\end{array}$ & 10 & 6 & 10 & 8 & 10 & 8 & 87 \\
\hline 3 & $\begin{array}{l}\text { Resolving issues involving } \\
\text { statistical applications in } \\
\text { everyday life. }\end{array}$ & 8 & 10 & 8 & 8 & 8 & 8 & 83 \\
\hline 4 & $\begin{array}{l}\text { Give examples of how data is } \\
\text { used in planning, monitoring, } \\
\text { and evaluation. }\end{array}$ & 8 & 0 & 10 & 10 & 10 & 6 & 73 \\
\hline
\end{tabular}

Table-I revealed that, the content knowledge of basic statistical concepts among students was excellent across all groups except for group two on item four. Several similar discoveries in the research, including: (i) every group was able to distinguish between descriptive and inferential statistics; (ii) three groups were still unsure about the difference between interval and ratio data; (iii) almost all of the groups explained why survey results differed due to differences in the sources used in the quick counting process.; and (iv) only one group did not provide an example for problem 4. The group that did not provide an example of data usage as a basis for planning, monitoring, and evaluation because they did not have enough time to complete the task. semester. This is in line with [12], who discovered that students who participated in PBL had better communication content knowledge on basic statistical concepts based on

The ability to comprehend the content of basic statistical conceptsis in line with the findings of the learning response questionnaire. Students was asked to respond to the learning response questionnaire. Students must complete ten questions with five response options, namely: (i) strongly agree; (ii) agree; (iii) disagree; (iv) disagree; and (v) strongly disagree. The following were the contents of the questionnaire: (i) learning makes me happy, so I will keep doing it.; (ii) learning motivates me to excel; (iii) learning raises my esteem; (iv) my understanding of the material being taught improves as a result of my learning.; (v) learning improves my ability to solve problems when they arise.; (vi) learning gives me more confidence in my ability to grow as a person; (vii) learning provides new experiences and knowledge; (viii) learning provides an opportunity for me to express ideas ; ix) learning enables me to work alone, or in groups; and x) learning challenges me to continue learning and improving myself.

Students respond to a questionnaire on their learning experience through the hand phone and Android application at the URL http://gg.gg/ResponB1. Fig. 10 illustrates the findings of the learning response questionnaire.

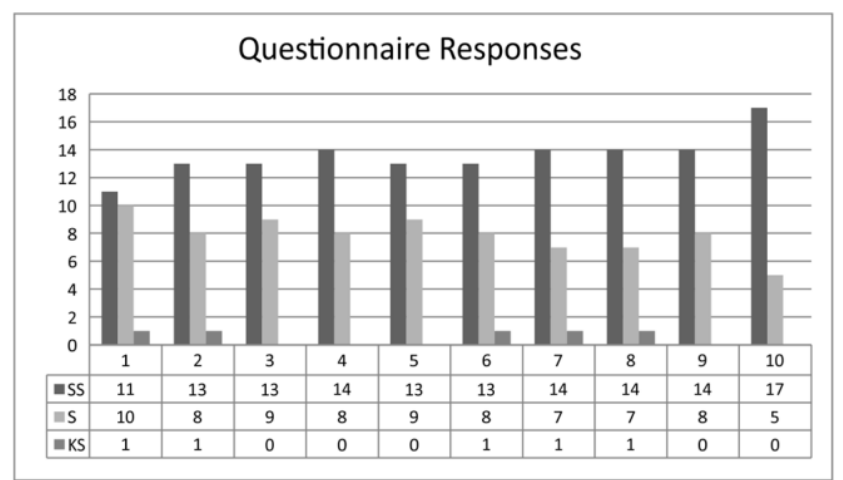

Fig. 10. Analysis of learning response questionnaire.

Fig. 10 shows the results of the learning response questionnaire, which show that the implementation of PBL through web-based apps received a very positive response; in fact, there were five questions $(3,4,5,9$, and 10$)$ in which $100 \%$ of the students agree with the statements. They believe that their education has increased their esteem, made it easier to understand what was being taught, made it easier to solve problems, given them opportunities to work independently and in groups, and propelled them to keep learning and progressing. Only one student disagreed with the replies to questions $1,2,6,7$, and 8 . This is in line with the findings of [13], who found that technology in education had an impact on learning motivation and success. Also, according to [14], using real-world issues in the classroom can help students develop an interest in learning.

\section{CONCLUSION}

Students' knowledge of basic statistical concepts improves as a result of using web-based apps in PBL. Each indicator demonstrates that students have a strong grasp of basic statistical concepts.

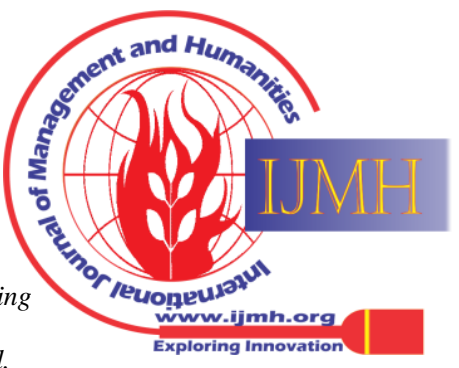


Additionally, the educational material used was very well-received. As a result of their experiences, students become more enthusiastic about learning, have a greater appreciation for things, are able to work independently and in groups, and are challenged to continue thriving.

\section{ACKNOWLEDGMENT}

The authors would like to express gratitude to Universitas Muhammadiyah Purwekorto, Indonesia and Universiti Pendidikan Sultan Idris Tanjong Malim, Malaysia for their support in the completion of this research.

\section{REFERENCES}

1. V. Dočekal, H. Tulinská, "The impact of technology on education theory". Procedia-Social and Behavioral Sciences, 174, 2015, pp. 3765-3771. DOI.10.1016/j.sbspro.2015.01.1111.

2. J. Underwood, The Impact of Digital Technology: A Review Of The Evidence of The Impact of Digital Technologies on Formal Education. Becta. Coventry, 2009. Retrieved from http://publications. becta.org.uk/display.cfm?resID=41343\&page $=1835$.

3. M. Simuforosa, "The impact of modern technology on the educational attainment of adolescents". International Journal of Education and Research, 1(9), 2013, pp. S1-S3.

4. T. Gok, "The positive and negative effects of digital technologies on students learning". The Eurasia Proceedings of Educational \& Social Sciences (EPESS), 2, 2015, pp. 173-177. DOI.10.1371/journal. pone. 0120011.

5. I.B. Olaore, "The impacts (positive and negative) of ICT on education in Nigeria". International Journal of Education, 4(23), 2014, pp. 154-156.

6. G. Gorghiu, L.M. Drăghicescu, S. Cristea, A.M. Petrescu, L.M. Gorghiu, "Problem-based learning-an efficient learning strategy in the science lessons context". Procedia - Social and Behavioral Sciences, 191, 2015, pp. 1865-1870. DOI.10.1016/j.sbspro.2015.04.570.

7. R.A.Tarmizi, S. Bayat, "Collaborative problem-based learning in mathematics: a cognitive load perspective". Procedia-Social and Behavioral Sciences, 32. 2012, pp. 344-350. DOI.10.1016/j.sbspro.

8. P.Tarrant,. A Practical Guide to Using Storyline Across the Curriculum, Taylor \& Francis Ltd, UK, 2019. DOI.10.4324/9781351055666-4

9. L. Barron, L. Wells, "Transitioning to the real world through problem-based learning: a collaborative approach to teacher preparation”. Journal of Learning in Higher Education, 9(2), 2013, pp.13-18.

10. R.I. Arends, Learning to Teach Ninty Edition. Mc Graw Hill. New York, 2012.

11. R. Marra, D. Jonassen, B. Palmer, S. Luft, "Why problem-based learning works: theoretical foundations". Journal on Excellence in College Teaching”, 25, 2015, pp. 221-238.

12. N.I. Abdullah, R.A. Tarmizi, R. Abu, "The effects of problem based learning on mathematics performance and affective attributes in learning statistics at form four secondary level". Procedia-Social and Behavioral Sciences, 8(5). 2010, pp. 370-376. DOI.10.1016/ j.sbspro.2010.12.052.

13. J.L. Harris, M.T. Al-Bataineh, A. Al-Bataineh, "One to one technology and its effect on student academic achievement and motivation". Contemporary Educational Technology, 7(4), 2016, pp. 368-381.

14. Y.D. Arthur, E.K. Owusu, S.A. Asiedu, "Connecting mathematics to real life problems: a teaching quality that improves student's mathematics interest". Journal of Research \& Method in Education, 8(4), 2018, pp. 65-71. DOI.10.9790/7388-0804026571.

\section{AUTHORS PROFILE}

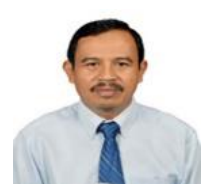

Ahmad, earned a Master degree in the Mathematics Education from UPI Bandung (2005), and a PhD in Mathematics Education (2018) from UPSI Malaysia. He has been a lecturer since 1990 in mathematics education at the Universitas Muhammadiyah Purwokerto, Central Java, Indonesia. He is active in mathematical education research and has published several articles specifically in classroom management in mathematics class, academic supervison of school headmaster, implementation of project based learning in mathematical class and many more.

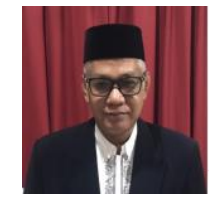

Zulkifley Mohamed, is a statistics professor at Universiti Pendidikan Sultan Idris, Tanjong Malim, Malaysia. He was awarded a MSc In Applied Statistics and Operational Reseach from University of Salford, UK. He received his $\mathrm{PhD}$ in Statistics from National University of Malaysia in 2007. He has published several articles in the area of statistics and education. He is also actively involved in research particularly in the field of statistics and education.

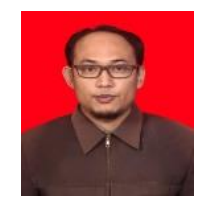

Fitrianto Eko Subekti, obtained a Master degree in Mathematics Education from the State University of Semarang in 2012. Since 2009 he has been a lecturer at Universitas Muhammadiyah Purwokerto, Central Java, Indonesia. He had published several articles in the Sinta 2 accredited National Journal and in reputable international proceedings. He is also actively involved in mathematics education research

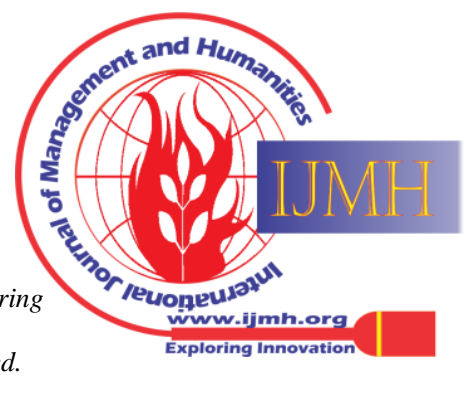

